\title{
Teaching Reformation and Practice on Mechanical Principle Course in Civilian-Run Colleges
}

\author{
Bo Jiang \\ Mechanical Engineering Institute, Changchun Guanghua University, Changchun, Jilin, China \\ key0725@sina.com
}

Keywords: Mechanical principle course; Teaching reformation; Study interest; Practice skill

\begin{abstract}
Combine with the requisition of mechanical engineering subject and education mode of civilian-run colleges, The reformation and exploration of mechanical principle course is carry out in optimizing teaching content, stimulating study interest of student, enhancing practice skill and innovation design ability, etc.
\end{abstract}

\section{Introduction}

With the development of society and increasing violent industry competition, multi-element trend of the current industry demand for professional talents is appearing in various professions. Obviously, for the talent market demand, from the actual situation, it is difficult for colleges and universities to make timely and effective countermeasure. In this situation, strengthen the basic theory of student learning, deepen comprehending and study of the course as well as industry, strengthen the practical ability is fit for the practical teaching of advanced education in our country. Mechanical principle course is a compulsory professional foundation course for mechanical engineering students. Main content of the course are mechanisms and machine dynamics. [1,2,3] The development and construction of this discipline go through eighty years, which condensed the wisdom of generations of scholars and researchers. Following the improvement of mechanical industry level, especially in advanced manufacturing technology, robot technology, electromechanical integration technology, mechanical professional talents' education of higher engineering colleges and universities put forward higher request to cultivating innovation design ability. Owing to the teaching content of mechanical principle course involved common questions of different machine and having a deciding function in new product exploitation, it is a non-substitutable important course for mechanical engineering profession. So it is imperative to reform the mechanical principle course. The teaching reforms and explorations of mechanical principle course in author's school as follows.

\section{Definite Teaching Objectives}

Mechanical principle course is a science for the study of mechanical foundation theory, is a backbone technology foundation course for all kinds of mechanical professions in colleges and universities, and occupies the core status in the knowledge required to create a new mechanical structure. The main task of the course is to enable students to master the basic theory, basic knowledge and basic skills on dynamics of mechanisms and machines, the preliminary draft capability with mechanical system movement plan, and the ability to design and analysis mechanisms and machines. It can strengthen students' ability to adapt to mechanical technical work and develop students' ability to creation and innovation on the cultivation of senior engineering and technical personnel. Teaching goal of the course is to cultivate students' ability in mechanical system movement scheme design and mechanical innovation design.

\section{Based on Teaching Materials, Optimizing Teaching Contents, Emphasis on 'Basic' Word}

Teaching material is the main basis for a teacher to arrange teaching content and teaching activities and students' study of the course, so the choice of teaching material is particularly important. The 
development of mechanical principle course materials of colleges and universities in china go through the three major reform, from the initial two mechanical principle teaching materials which respectively written by Northwestern Polytechnic University and Nanjing Institute of Technology reference to the Soviet union, according to different system, to the current many teaching materials of all sorts of different characteristics. These give the larger space for the selection of mechanical principle course material [4]. Therefore, we should select a suitable teaching material and arrange proper teaching content according to the characteristics that civilian-run college students' foundation is weak, and theirs' study interest is not high. When arranging the teaching contents, we should highlight 'basic' word, emphasize the teaching of basic theories, basic knowledge and basic skills, and weaken the content of formula's derivation that it is not easy to understand for student. At the same time, we should optimize the teaching content, the theory involved in the previous theoretical mechanics and physics course should be deep in combination with the mechanism design. Based on the above ideas, we made the following arrangement of teaching content of mechanical principle. First, for mechanisms part, we focused on explaining the composing principle of mechanisms, conventional mechanisms' design and analysis, such as linkage mechanism, cam mechanism, gear mechanism, and gear train, etc. Second, for machine dynamics part, we focused on explaining the mechanical balance and mechanical speed fluctuation and adjustment. Third, for mechanism motion analysis and force analysis part, which are involved in the theoretical mechanics and physics, and as an important teaching content of theoretical mechanics course. So for this part of the teaching process we should try to avoid repeating the interpretation of theoretical content, focus on the introduction of the current analytical method widely used in practical engineering design and engineering analysis software ADAMS, especially the introduction of the use of specific examples, so as to promote students' ability to use basic theory and basic knowledge solution actual problem and strengthen the students' ability to use the basic skills of engineering software analysis to solve practical problems.

\section{Stimulate Students' Interest in Learning and Desire for Seeking Knowledge}

Science giant Einstein once said: 'interest is the best teacher'. Our country's classic work 'the analects' also say 'The person who knows not as good as well knower, good knower not as good as the person happy to know'. It's all said the importance of interest in learning. It is same for the mechanical principle course teaching how to stimulate and cultivate the students' interest in learning.

Mix Chinese Elements. Mix the elements of China into the teaching of mechanical principle course, and strengthen the education of the students' patriotic sentiment. The traditional view is that Chinese civilization compared with the western civilization is in a state of lag. There is no denying the fact that view to a certain extent, reflects the understanding of Chinese engineering technical level, but with the birth of Mr. Joseph Needham's work "science and civilization in China", it has attracted the attention of people to the science and technology of China. In fact, achievement in the history of Chinese engineering technology is remarkable, but unfortunately, the ancient Chinese scientists do not pay attention to theoretical summary and inheritance, it has caused many great inventions didn't get a good inheritance. Chinese ancient machine covering a wide range and with a large number, there are agricultural machinery, handicraft industry machinery, lifting machinery, etc. It has a high level, and part of them have the world advanced level, such as South-pointing chariot, mileage drum wagon, incense burner in the quilt, water-driven astronomical clock tower, and so on. A high level of Chinese machinery make the Chinese civilization as the world's advanced civilization, China never lack of excellent talents. The good news is that in this respect in recent years, academics have made a meaningful exploration [5,6]. Look from actual teaching effect, combines Chinese elements in mechanical principle course teaching, which let students understand ancient Chinese machinery, more conducive to stimulate students' patriotic enthusiasm and the strong national pride, and has the positive significance to promote students' learning interest and desire for seeking knowledge.

Intervention Era Elements, Connection with the Engineering Design Practice. On the basis 
of traditional graphic method design, the introduction of analytic method and the analysis of engineering design with professional software such as computer aided design method, enhance and broaden the student's ability to use design tool ADAMS software [7,8]. Fig.1 shows a simulation model of shaper mechanism and Fig. 2 shows shaper ram movement characteristics curve. Combined with the mechanical innovation design idea, on the basis of mechanism analysis and design is commonly used, increase the interpretation of the content such as mechanism of combination and innovation design, it's better for enhance students' innovative design ability of mechanical product movement scheme.
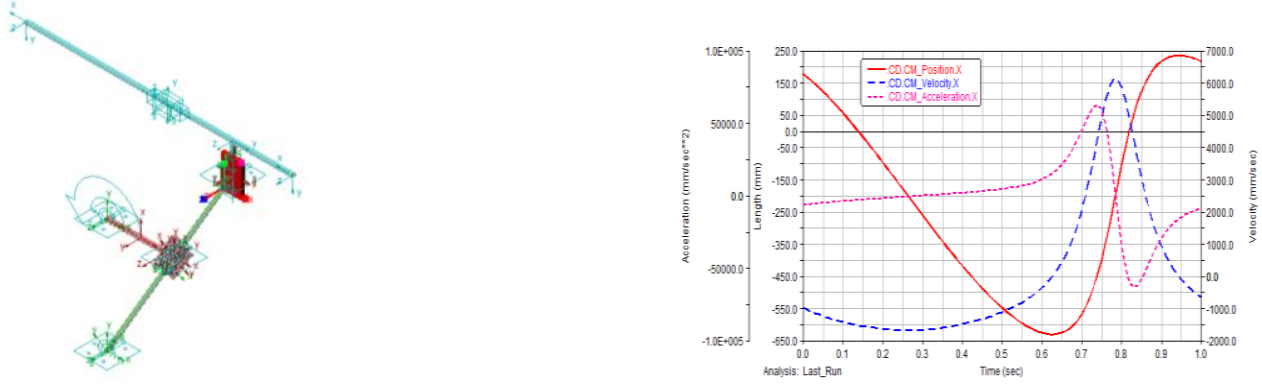

Figure 1. Simulation model of shaper mechanism Figure 2. shaper ram movement characteristics curve

Simplify the Complicated Theory Teaching Content, and Enhance the Students' Classroom Participation. We divided students into study groups based on a unit 3 to 4 people, optimized grouping of students based on the teachers' know about them. Teacher assigned students extracurricular learning tasks, and then Students through the library and the Internet data such as books and papers to complete the task, meanwhile sorted them into electronic presentation. A representative or representatives of each group showed the results to the students in the class, the rest of the team can ask questions and discussion, and then teacher gave appropriate comments. Sent representatives to show you in class, the rest of the team can play debate, supplemented by appropriate comments on teachers, PK results recorded in $40 \%$ of the final grade. Interaction between students, greatly improved the efficiency of the course. The teaching method was organized by combination of teaching and discussions, properly used heuristic teaching, pay attention to the cultivation of the team cooperation ability $[9,10]$. It not only could exercise the student's ability to collect and organize data and information, but also was useful to cultivate the students' team cooperation spirit, and improve the students' autonomous learning awareness.

\section{Strengthen the Practice Teaching Content}

Strengthen the Reform of Experiment Content and Curriculum Design. In experiments and curriculum design practice teaching, we increased the comprehensive innovation design experiment and close to the practice of engineering curriculum design topics, practice has proved that it is useful to strengthen the students' practical operating ability and the quality and ability to solve the problem of the engineering practice. Civilian-run colleges have flexible system and the characteristic of quick reply speed to teaching reform. To meet the teaching need of comprehensive innovation experiment in experiment course, colleges purchased planar mechanism creative combination and test-bed, space mechanism innovation design test bench and so on latest mechanical principle experiment equipment. Through several rounds of teaching practice, it was proved that the opening of these experiments has played a good role in promoting the student's ability of comprehensive use and design.

Guide and Organize Students to Take an Active Part in the Mechanical Innovation Design and Engineering Comprehensive Ability Competition. Teachers penetrated the innovation design method into daily teaching activity, guided students to take an active part in college students' mechanical innovation design competition, these stimulated students' interest in learning. At the 
same time, through the competition to improve the students' innovative consciousness and practical ability, achieve good results. In the fourth session to the seventh session of the national college students' mechanical innovation design competition, the students in our school won the first prize in the national 2, the first prize at the provincial 5, the second prize at the provincial 14.

\section{Conclusion}

Organic combination of the civilian-run colleges of the characteristics of flexible and resourceful, talent training mode and requirements, to Simplify the teaching content of mechanical principle course, focus on students' basic theory, basic knowledge and basic skills training, pay attention to the reinforcement of close combination of theory teaching content and comprehensive practice, strengthen the team cooperation consciousness, participate in social practice and course contests, the practice result achieved the goal that we expect. Compared with the traditional cramming teaching, these reforms did raise the students' comprehensive ability in practice and innovation design. Though it also has many shortcomings, but we have enough confidence to predict, with the quickening pace of mechanical principle teaching reform and exploration, the future teaching reform and exploration of the mechanical principle will make greater achievements.

\section{References}

[1] H.J. Zou, Q.H. Liang: Machine Design and Research, Vol.27 (2011) No.1, p.117. (in Chinese)

[2] C.L. Zhang: Mechanical Principle(Higher Education Press, China, 2006).(in Chinese)

[3] Y.X. Pan, Mechanical Principle (Huazhong University of Science \& Technology Press, China, 2015). (in Chinese)

[4] Q.L. Cao, S.D. Shen, etc.: Journal of Nantong Institute of Technology (Social Science Edition), , vol. 8(2002), No. 4, p.64. (in Chinese)

[5] H.J. Zou: China University Teaching, No.3 (2000). (in Chinese)

[6] W.J. Ge: University Teaching in China, No.12 (2007). (in Chinese)

[7] Ce Zhang: University Teaching in China, No.10 (2006). (in Chinese)

[8] S.Y. Song: ADAMS in the Application of Mechanical Designs (National Defense Industry Press, China, 2015). (in Chinese)

[9] Q. Q. Lu: The Construction and Practice of Teaching Method for Mechanical Principles Integration Course Based on CDIO. Advanced Materials Research. Vol.591-593(2012), p.2171.

[10] J. Xie: Developing students' abilities in engineering design through the teaching of mechanism and machine theory. International Journal of Mechanical Engineering Education, Vol.41(2013), No.4, p.360. 